\title{
A phylogenetic study of canine parvovirus type 2c in midwestern Brazil ${ }^{1}$
}

\author{
Danúbia S. Fontana², Paulo Ricardo D. Rocha ${ }^{3}$, Raquel A.S. Cruz ${ }^{2}$, Letícya L. Lopes², \\ Andréia L.T. Melo ${ }^{2}$, Marcelo M. Silveira ${ }^{2}$, Daniel M. Aguiar ${ }^{2}$ and Caroline A. Pescador ${ }^{2 *}$
}

\begin{abstract}
Fontana D.S., Rocha P.R.D., Cruz R.A.S., Lopes L.L., Melo A.L.T., Silveira M.M., Aguiar D.M. \& Pescador C.A. 2013. A phylogenetic study of canine parvovirus type 2c in midwestern Brazil. Pesquisa Veterinária Brasileira 33(2):214-218. Departamento de Clínica Médica Veterinária, Faculdade de Agronomia, Medicina Veterinária e Zootecnia, Universidade Federal de Mato Grosso, Av. Fernando Corrêa da Costa 2367, Cuiabá, MT 78069-900, Brazil.E-mail: capescador@ufmt.br

Since the late 1970s, canine parvovirus type 2 (CPV-2) has emerged as a causative agent of fatal severe acute hemorrhagic enteritis in dogs. To date, three antigenic types of CPV2 were described worldwide $(\mathrm{CPV}-2 \mathrm{a} / \mathrm{b} / \mathrm{c})$. This study was conducted to determine the variants of CPV-2 circulating in dogs from the Cuiabá Municipality in Midwestern Brazil. Out of 50 fecal samples, collected between 2009 and 2011, 27 tested positive for CPV-2. A 583 bp fragment of the VP2 gene was amplified by PCR, 13 representative samples were analyzed further by DNA sequencing. All strains were characterized as CPV-2c, displayed a low genetic variability although observed several amino acid substitution. These findings indicated that CPV-2c has been circulating in dogs from the Cuiabá Municipality in Midwestern Brazil.
\end{abstract}

INDEX TERMS: Canine parvovirus, enteritis, PCR, DNA, sequencing.

RESUMO.- [Estudo filogenético do parvovírus canino tipo 2c no Centro-Oeste do Brasil.] Desde o final dos anos de 1970, o parvovírus canino tipo 2 (CPV-2) tem emergido como agente de severa e fatal enterite hemorrágica, principalmente em cães com idade inferior a seis meses. Três variantes antigênicas de CPV-2 foram descritas mundialmente (CPV-2a/b/c). 0 objetivo do estudo foi determinar a presença do CPV-2 e suas variantes circulantes em cães no Município de Cuiabá, Centro-oeste, Brasil. Das 50 amostras fecais, coletadas entre 2009 e 2011, 27 foram positivas para CPV-2 na PCR, sendo 13 analisadas pelo sequenciamento de um fragmento de 583 pares de base do gene VP2. Todas as cepas foram caracterizadas como CPV-2c e apresentaram baixa variabilidade genética. Estes achados indicaram que o CPV-2c está circulando na

\footnotetext{
${ }^{1}$ Received on July 3, 2012.

Accepted for publication on August 31, 2012.

${ }^{2}$ Departamento de Clínica Médica Veterinária, Faculdade de Agronomia, Medicina Veterinária e Zootecnia, Universidade Federal de Mato Grosso (UFMT), Av. Fernando Corrêa da Costa 2367, Cuiabá, MT 78069-900, Brazil.*Corresponding author: capescador@ufmt.br

${ }^{3}$ Departamento de Patologia Animal, Faculdade de Medicina Veterinária, Universidade de Torino (Unito), Via Leonardo Da Vinci 44, Grugliasco, Torino 10095, Itália.
}

população canina do Município de Cuiabá, Região Centro-Oeste do Brasil.

TERMOS DE INDEXAÇÃO: Parvovirus canino, enterites, PCR, DNA, sequenciamento.

\section{INTRODUCTION}

Canine parvovirus (CPV) type 2 emerged around 1978 and is one of the most pathogenic etiologic agents in dogs. This virus causes hemorrhagic diarrhea, vomiting and lymphopenia (Appel et al. 1979). After the initial appearance of CPV-2 in the mid-1980s, 2 antigenic variants were identified, CPV-2a and CPV-2b, which can be distinguished by monoclonal antibodies and at least five or six amino acid substitutions in the VP2 capsid protein gene (Parker et al. 2001).

More recently, another antigenic variant, CPV-2c, was described in dogs from Italy; this variant differs from CPV$-2 b$ by one amino acid change from Asp to Glu at position 426 (Buonavoglia et al. 2001). The same variant was later detected in other European countries (Decaro et al. 2007), Asia (Nakamura et al. 2004), Australia (Meers et al. 2007), North and South America countries including Brazil (Hong et al. 2007, Pérez et al. 2007, Streck et al. 2009). 
CPV variants are circulating worldwide, and their relative frequencies vary according to the geographic region analyzed and the time of sample collection (Pérez et al. 2012). Pinto et al. (2012) demonstrated that CPV-2c has been the main subtype detected in the canine population of some regions of Brazil, as previously found in the Uruguay (Pérez et al. 2007), Italy (Decaro et al. 2007), Germany (Decaro et al. 2011a), and Argentina (Calderón et al. 2011). Therefore, it is important to identify emerging $\mathrm{CPV}$ variants and developing preventive measures to control the spread of CPV-2 variants. In this context, the objective of the current study was to identify the CPV variants present in the Cuiabá Municipality of Midwestern Brazil, between the years 2009 and 2011.

\section{MATERIALS AND METHODS}

A total of 50 domestic dogs (21 vaccinated and 29 unvaccinated against canine parvovirosis) ranging from 1 to 36 months old that presented clinical signs suggestive of CPV infection were selected for this study. The dogs were necropsied in the Laboratory of Veterinary Pathology of Federal University of Mato Grosso (UFMT), Cuiabá, Mato Grosso State, Brazil, between February 2009 and August 2011. At necropsy, $2 \mathrm{~mL}$ fecal samples were collected in plastic tubes and frozen at $-20^{\circ} \mathrm{C}$ until use. Fragments of the small intestine were also collected, fixed in $10 \%$ buffered formalin and processed according to standard histological methods. Paraffin-embedded tissue sections ( $5 \mu \mathrm{m})$ were stained with hematoxylin and eosin and microscopically evaluated with an optic microscope.

For DNA extraction, the fecal samples were suspended $(10 \%$, $\mathrm{w} / \mathrm{v}$ ) in phosphate-buffered saline (PBS, $0.1 \mathrm{M}, \mathrm{pH}$ 7.2) and subsequently clarified by centrifuging at 4,000 $\mathrm{x} g$ at $4 \mathrm{C}$ for $15 \mathrm{~min}$. The supernatants were homogenized in chloroform at a final concentration of $10 \%$, centrifuged at $1,000 \times \mathrm{g}$ at $4 \mathrm{C}$ for $15 \mathrm{~min}$ and diluted 1:10 in distilled water (Decaro et al. 2006). DNA was also extracted from a commercial vaccine (Lema Injex Biologic Tri Baby Vac $^{\circledR}$, CPVC780/916 ATCC) according to the method of Sangioni et al. (2005) and used as a positive control. Ultrapure water was used as a negative control. PCR was performed using the 555for and $555 \mathrm{rev}$ primer set that amplify a $583 \mathrm{bp}$ fragment of the VP2 gene (nucleotides 4003-4585) (Buonavoglia et al. 2001). The PCR amplification was performed using Taq recombinant polymerase (Invitrogen ${ }^{\circledR}$, USA) in a thermocycler (MyCycler ${ }^{\circledR}$, BIO-RAD, USA), as reported by Calderón et al. (2011). To investigate the heterogeneity of the virus population, the amplified products of 13 representative samples were selected for sequencing and were purified using the GFX PCR DNA \& Gel Band Purification Kit (GE Healthcare $\AA_{\text {, }}$ Buckinghamshire, UK). The sequencing reactions were performed with the same primers as those used for PCR amplification on an automated DNA sequencer (ABI-PRISM 3100 Genetic Analyzer, Applied Biosystems, Germany). Alignments and sequence analysis were performed in molecular evolutionary genetic analysis software (MEGA version 5.0) (Tamura et al. 2011) using the ClustalW algorithm. In addition, a phylogenetic tree was constructed by the neighbor-joining (NJ) method, and bootstrap analyses were conducted using 1000 replicates. The evolutionary distances were computed using the Maximum Composite Likelihood method (Tamura et al. 2011). For sequence comparison, the nucleotide sequences of CPV-2 (M38245), CPV-2a (M24003), CPV-2b (M74849) and CPV-2c from 11 countries including Brazil were retrieved from GenBank. All of the sequences generated in this study were deposited in GenBank (accession numbers: JQ429273-JQ429285).

Information regarding the breed, sex, age, vaccination status and CPV-2 sequencing results for the 13 representative samples are shown in Table 1.

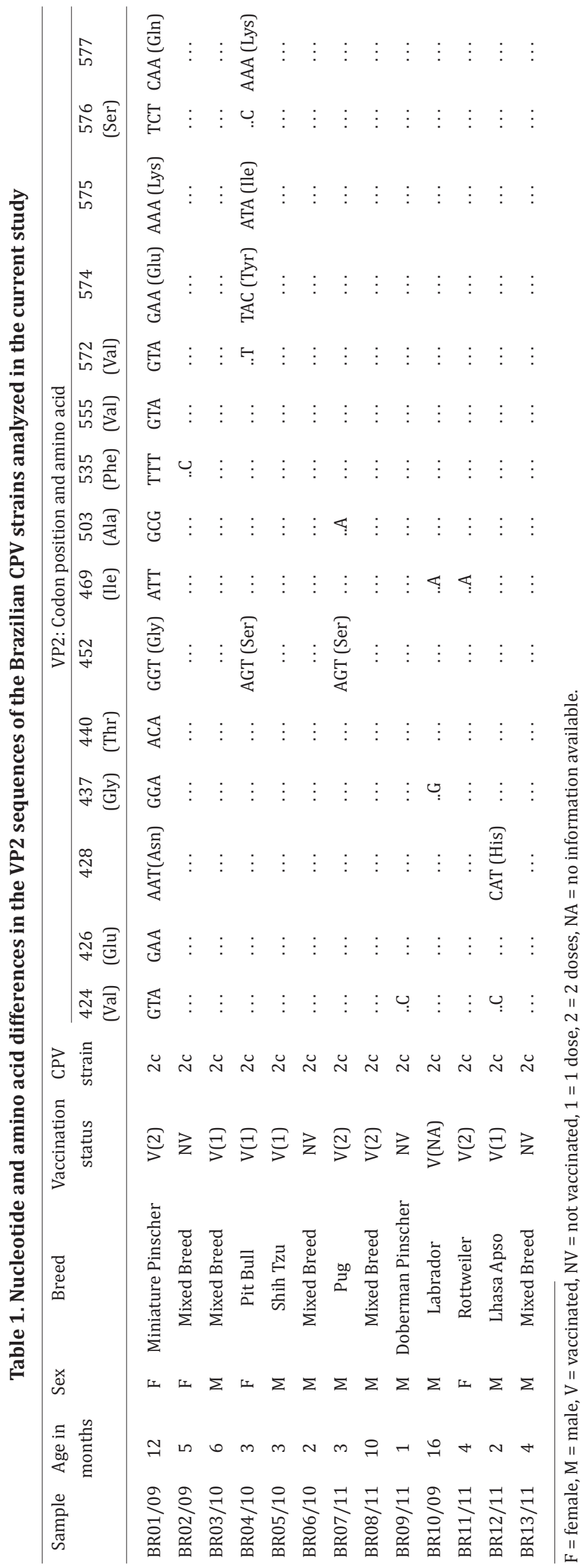




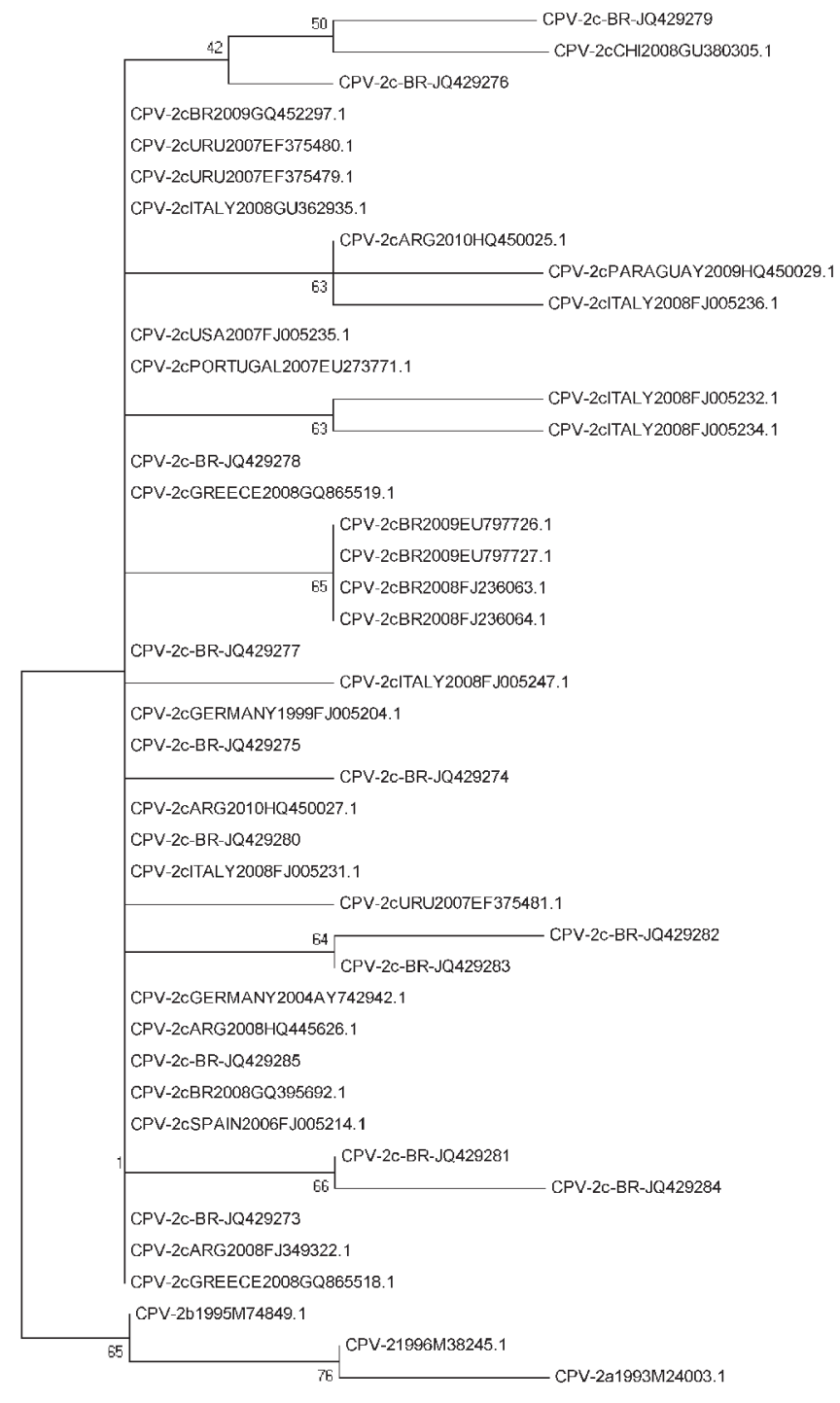

$\lcm{0.0005}$

Fig.1. Neighbor-joining tree (MEGA 5.0) based on the studied canine parvovirus sequences and the following reference sequences: M38245 (CPV-2), M24003 (CPV-2a), M74849 (CPV-2b), HQ450025 (CPV-2c, Argentina), HQ450027 (CPV-2c, Argentina), HQ445626 (CPV-2c, Argentina), FJ349322 (CPV-2c, Argentina), FJ005247 (CPV-2c, Italy), FJ236063 (CPV-2c, Brazil), FJ236064 (CPV-2c, Brazil), EU797726 (CPV-2c, Brazil), EU797727 (CPV-2c, Brazil), GU380305 (CPV-2c, China), FJ005204 (CPV-2c, Germany), FJ005231 (CPV-2c, Italy), FJ005232 (CPV-2c, Italy), FJ005234 (CPV-2c, Italy), FJ005236 (CPV-2c, Italy), EF375479 (CPV-2c, Uruguay), EF375480 (CPV-2c, Uruguay), FJ005235 (CPV-2c, USA), GQ395692 (CPV-2c, Brazil), GQ452297 (CPV-2c, Brazil), GU362935 (CPV-2c, Italy), HQ450029 (CPV-2c, Paraguay), EU273771 (CPV-2c, Portugal), EF375481 (CPV-2c, Uruguay), AY742942 (CPV-2c, Germany), GQ865518 (CPV-2c, Greece), GQ865519 (CPV-2c, Greece) and FJ005214 (CPV-2c, Spain). Statistical support was provided by bootstrapping with 1000 replicates. The scale bar indicates the estimated numbers of nucleotide substitutions per site.

\section{RESULTS}

Of the 50 fecal dog samples, 27 (54\%) were positive for CPV by PCR. The clinical signs observed in positive dogs included vomiting, anorexia, lethargy and liquid hemorrhagic diarrhea. Macroscopic examination showed mucosal hyperemia and roughness of the serosa of the small intestine, with hemorrhagic content in the intestinal lumen. The most significant intestinal lesion upon microscopic examination was severe necrotic enteritis with fusion of the intestinal villi.

The 13 sequenced CPV samples revealed the presence of a GAA codon at position 426 of the VP2 protein, which codes for glutamate, indicating that these strains were CPV-2 c. The results of the amino acid sequence analysis showed that there was a low level of overall variability among the analyzed VP2 sequences, with only five amino acid changes affecting the VP2 protein. A non-synonymous mutation at amino acid residue 428 (Asn $\rightarrow$ His) was observed in sample BR 12/11. There was a single nucleotide polymorphism at position 4142 in two clinical samples (BR 04/10 and BR $07 / 11$ ), corresponding to a transition ( $\mathrm{G}$ to $\mathrm{A})$ in the first position of codon 452. One sample (BR 04/10) exhibited three unique residues (Tyr574, Ile575 and Lys577).

Several single nucleotide changes were found among the CPV-2c sequences: A424C in samples BR 09/11 and BR 12/11, A437G in BR 10/09, T469A in BR 10/09 and BR $11 / 11$, G503A in BR 07/11, A572T in BR 04/10, T535C in BR 02/09 and T576C in BR 04/10. All of these nucleotide changes were in the third codon position and did not change the amino acid. All of the sequenced samples presented the typical amino acid $\mathrm{T}$ at the 440 position, whereas a $\mathrm{V}$ residue was found in all CPV strains in the 555 position.

Six of the thirteen CPV-2c isolates were found to be phylogenetically closely related to European, North and South American isolates recovered between 1993 and 2010 (sequences obtained from GenBank; highlighted in Figure 1).

\section{DISCUSSION}

From 1980 to the present, CPV-2a and 2b have been the most significant $\mathrm{CPV}$ variants circulating in the Southeast region of Brazil (Pereira et al. 2007, Castro et al. 2011). However, CPV-2c has been detected in epidemiological surveys conducted in South America (Pérez et al. 2007) including Southern (Streck et al. 2009) and Southeast region of Brazil (Castro et al. 2010). This article constitutes the first to provide information about CPV-2c infection in dogs from the Mato Grosso State in Midwestern Brazil.

Most of the sequenced samples (69.2\%) were derived from 1 to 5 month-old puppies with variable vaccination statuses. The presence of CPV gastroenteritis in vaccinated animals has been reported previously (McElligott et al. 2010) and could possibly indicate a gap in the protective status of the puppies, most likely due to low levels of maternal antibodies or an immature immune system that is unable to respond properly to vaccination (Calderón et al. 2011). The interference of residual maternally derived antibodies with the vaccine virus may also explain the cases of CPV infection observed in vaccinated dogs (Decaro et al. 2006).

The clinical and pathologic findings of the present study were similar to those presented in previous reports (Cooper et al. 1979, Evermann et al. 2005, Oliveira et al. 
2009). In comparison to the original type 2 , the antigenic variants $2 a$ and $2 b$ have been reported to be shed in the feces at much higher titers and to cause a more severe disease (Decaro et al. 2005a). In addition, Decaro et al. (2005b) have demonstrated in German shepherds dogs naturally infected with a field isolate of CPV-2c, that pups displayed clinical signs of parvovirosis (mucoid or watery diarrhea and transient leukopenia), however none showed either hemorrhagic diarrhea or vomiting. On the other hand, Spibey et al. (2008) carried out an experimental infection of beagles dogs with a field isolate of CPV-2c that all infected control dogs became severely ill and displayed leukopenia from day 4 post-infection. Although the necropsied animals of this study showed severe macroscopic and microscopic intestinal lesions, the authors cannot suggest that CPV-2c could be associated with more severe disease than CPV-2a and CPV-2b due to the low number of samples analyzed. Indeed, it is reasonable to think that all three variants have a similar pathogenetic potential, which can increase depending on particular field conditions (age, immunological status, stressing factors) (Decaro \& Buonavoglia 2011b).

The synonymous substitution found at codon 503 of VP2 in the isolate BR07/11 was previously described in a Chinese CPV-2c strain (GU380305) collected in 2009, suggesting that some Brazilian CPV-2c strains may share a common ancestor with this strain. However, the VP2 changes Asn $\rightarrow$ His at residue 428, Gly $\rightarrow$ Ser at residue 452, Glu $\rightarrow$ Tyr at residue 574, Lys $\rightarrow$ Ile at residue 575 and Gln $\rightarrow$ Lys at residue 577 , as well as other single nucleotide changes, have not been reported in any CPV-2c strain to date. According to Pereira et al. (2007), Brazilian variants with a complete repertoire of mutations in the VP1/VP2 gene emerged only after the 1990s, when dogs were regularly vaccinated, and most of these mutations are consistent with a diversification process mediated by local adaptation.

In accordance with Pinto et al. (2012), the amino acid substitution Thr440Ala was not observed in any CPV-2c sequences, as previously described in CPV-2a and CPV-2b strains from Italy (Battilani et al. 2002), India (Chinchkar et al. 2006), Korea (Kang et al. 2008), and in CPV-2c strains from Argentina (Calderón et al. 2011) and Italy (Decaro et al. 2009). The 440 position is located at an important VP2 domain, undergoing positive selection and envolved independently in different populations (Decaro et al. 2007).

All CPV strains showed a V residue in the 555 position which has been described by Calderón et al. (2011) and Pinto et al. (2012). The Ile555Val change could possibly indicate a reversion to the original CPV-2 (Martella et al. 2006).

Phylogenetic analysis of the variants circulating in the canine population of Cuiabá Municipality revealed a group composed of similar variants to those from other Brazilian States, Italy, Uruguay, Paraguay, Argentina, China, United States, Portugal, Greece, Germany and Spain, indicating that this variant as cosmopolitan. Such findings also suggest that the variants from Brazil share a common ancestor with variants from different continents, however some substitutions affecting Brazilian CPV-2c strains have been already reported.
In conclusion, although few sequences were analyzed in this study, the results demonstrated that CPV-2c has been circulating and causing disease in dogs of Cuiabá Municipality. Additional research is necessary to estimate the overall prevalence, distribution and genetic diversity of CPV-2 variants in Brazil.

Acknowledgements.- To Manoel Luis de Arruda for technical assistance with tissue processing for the histological analyses. We are very grateful to Dr. Luciano Nakazato and students Daniel Guimarães Ubiali and Marconni Victor da Costa Lana from the Federal University of Mato Grosso, Brazil, for their invaluable help.

\section{REFERENCES}

Appel M.J.G., Scott F.W. \& Carmichael L.E. 1979. Isolation and immunisation studies of a canine parvo-like virus from dogs with haemorrhagic enteritis. Vet. Rec. 105:156-159.

Battilani M., Ciulli S., Tisato E. \& Prosperi S. 2002. Genetic analysis of canine parvovirus isolates (CPV-2) from dogs in Italy. Virus Res. 83:149-157.

Buonavoglia C., Martella V., Pratelli A., Tempesta M., Cavalli A., Buonavoglia D., Bozzo G., Elia G., Decaro N. \& Carmichael L. 2001. Evidence for evolution of canine parvovirus type 2 in Italy. J. Gen. Virol. 82:3021-3025.

Calderón M.G., Romanuttia C., D’Antuonoa A., Kellerb L., Mattiona N. \& La Torre J. 2011. Evolution of canine parvovirus in Argentina between years 2003 and 2010: CPV2c has become the predominant variant affecting the domestic dog population. Virus Res. 157:106-110.

Castro T.X., Costa E.M., Leite J.P.G., Labarthe N.V. \& Cubel Garcia R.C.N. 2010. Partial VP2 sequencing of canine parvovirus (CPV) strains circulating in the state of Rio de Janeiro, Brazil: detection of the new variant CPV-2c. Braz. J. Microbiol. 41:1093-1098.

Castro T.X., Costa E.M., Leite J.P., Labarthe N.V. \& Cubel Garcia R.C. 2011. Monitoring of canine parvovirus (CPV) strains detected in vaccinated puppies in Brazil. Res. Vet. Sci. 90:336-340.

Chinchkar S.R., Mohana Subramanian B., Hanumantha Rao N., Rangarajan P.N., Thiagarajan D. \& Srinivasan V.A. 2006. Analysis of VP2 gene sequences of canine parvovirus isolates in India. Arch. Virol. 151:18811887.

Cooper B.J., Carmichael L.E., Appel M.J.G. \& Greisen H. 1979. Canine viral enteritis. II. Morphologic lesionsin naturally occuring parvovirus infection. Cornell Vet. 69:134-144.

Decaro N., Campolo M., Desario C., Elia G., Martella V., Lorusso E. \& Buonavoglia C. 2005a. Maternally-derived antibodies in pups and protection from canine parvovirus infection. Biologicals 33:259-265.

Decaro N., Desario C., Campolo M., Elia G., Martella V., Ricci D., Lorusso E. \& Buonavoglia C. 2005b. Clinical and virological findings in pups naturally infected by canine parvovirus type 2 Glu-426 mutant. J. Vet. Diagn. Invest. 17:133-138.

Decaro N., Martella V., Desario C., Bellacicco A.L., Camero M., Manna L., D’Aloja D. \& Buonavoglia C. 2006. First detection of canine parvovirus type $C$ in pups with haemorragica enteritis in Spain. J. Vet. Med. 53:468472 .

Decaro N., Martella V., Elia G., Desario C., Campolo M., Lorusso E., Colaianni M.L., Lorusso A. \& Buonavoglia C. 2007. Tissue distribution of the antigenic variants of canine parvovirus type $C$ in dogs. Vet. Microbiol. 121:39-44.

Decaro N., Desario C., Parisi A., Martella V., Lorusso A., Micopullo A., Mari V., Colaianni M.L., Cavalli A., Di Trani L. \& Buonavoglia C. 2009. Genetic analysis of canine parvovirus type 2c. Virology 385:5-10.

Decaro N., Desario C., Billi M., Mari V., Elia G., Cavalli A., Martella V. \& Buonavoglia C. 2011a. Western European epidemiological survey for parvovirus and coronavirus infections in dogs. Vet. J. 187:195-199.

Decaro N. \& Buonavoglia C. 2011b. Canine parvovirus: A review of epidemiological and diagnostic aspects, with emphasis on type 2c. Vet. Microbiol. 155:1-12. 
Evermann J.F., Abbott J.R. \& Han S. 2005. Canine coronavirus associated puppy mortality without evidence of concurrent canine parvovirus infeccion. J. Vet. Diagn. Invest. 17:610-614.

Hong C., Decaro N., Desario C., Tanner P., Pardo M., Sanchez S., Buonavoglia C. \& Saliki J. 2007. Occurrence of canine parvovirus type C in the United States. J. Vet. Diagn. Invest. 19:535-539.

Kang B.K., Song D.S., Lee C.S., Jung K.I., Park S.J., Kim E.M. \& Park B.K. 2008. Prevalence and genetic characterization of canine parvoviruses in Korea. Virus Genes 36:127-133.

Martella V., Decaro N. \& Buonavoglia C. 2006. Evolution of CPV-2 and implication for antigenic/genetic characterization. Virus Genes 33:11-13.

McElligott S., Collins P.J., Sleator R.D., Martella V., Decaro N., Buonavoglia C. \& O'She H. 2010. Detection and genetic characterization of canine parvoviruses and coronaviruses in southern Irelan. Arch. Virol. 156:495503.

Meers J., Kyaw-Tanner M., Bensink Z. \& Zwijnenberg R. 2007. Genetic analysis of canine parvovirus from dogs in Australia. Aust. Vet. J. 85:392-396.

Nakamura M., Tohya Y., Miyazawa T., Mochizuki M., Phung H.T., Nguyen N.H., Huynh L.M., Nguyen L.T., Nguyen P.N., Nguyen P.V., Nguyen N.P. \& Akashi H. 2004. A novel antigenic variant of Canine parvovirus from a Vietnamese dog. Arch. Virol. 149:2261-2269.

Oliveira E.C., Pescador C.A., Sonne L., Pavarini S.P., Santos A.S., Corbellini L.G. \& Driemeier D. 2009. Análise imuno-histoquímica de cães naturalmente infectados pelo parvovírus canino. Pesq. Vet. Bras. 29:131-136.

Parker J.S.L., Murphy W.J., Wang D., O’Brien S.J. \& Parrish C.R. 2001. Canine and feline parvoviruses can use human or feline transferrin receptors to bind, enter and infect cells. J. Virol. 75:3896-3902.
Pereira C.A., Leal E.S. \& Durigon E.L. 2007. Selective regimenshift and demographic growth increase associated with the emergence of high-fitness variants of canine parvovirus. Infect. Genet. Evol. 7:399-409.

Pérez R., Francia L., Romero V., Maya V., Lopez I. \& Hernandez M. 2007. First detection of canine parvovirus type $2 \mathrm{c}$ in South America. Vet. Microbiol. 124:147-152.

Pérez R., Bianchi P., Calleros L., Francia L., Hernández M., Maya L., Panzera Y., Sosa K. \& Zoller S. 2012. Recent spreading of a divergent canine parvovirus type 2a (CPV-2a) strain in a CPV-2c homogenous population. Vet. Microbiol. 155:214-219.

Pinto L.D., Streck A.F., Gonçalves K.R., Souza C.K., Corbellini A.O., Corbellini L.G., Canal C.W. 2012. Typing of canine parvovirus strains circulating in Brazil between 2008 and 2010. Virus Res. 165:29-33.

Sangioni L.A., Horta M.C., Vianna M.C.B., Gennari S.M., Soares R.M., Galvão M.A.M., Schumaker T.T.S., Ferreira F., Vidotto O. \& Labruna M.B. 2005. Rickettsial infection in animals and Brazilian spotted fever endemicity. Emerg. Infect. Dis. 11:265-270.

Spibey N., Greenwood N.M., Sutton D., Chalmers W.S. \& Tarpey I. 2008. Canine parvovirus type 2 vaccine protects against virulent challenge with type $2 c$ virus. Vet. Microbiol. 128:48-55.

Streck A.F., Souza C.K., Gonçalves K.R., Zang L., Pinto L.D. \& Canal C.W. 2009. First detection of canine parvovirus type $2 \mathrm{c}$ in Brazil. Braz. J. Microbiol. 40:465-469.

Tamura K., Peterson D., Peterson N., Stecher G., Nei M. \& Kumar S. 2011. MEGA5: Molecular Evolutionary Genetics Analysis using Maximum Likelihood, Evolutionary Distance, and Maximum Parsimony Methods. Mol. Biol. Evol. 28:2731-2739. 